\title{
Simulative study of simple ring resonator-based brewster plate for power system operation stability
}

\author{
IS Amiri ${ }^{1}$, Ahmed Nabih Zaki Rashed ${ }^{2}$ \\ ${ }^{1}$ Computational Optics Research Group, Advanced Institute of Materials Science, Vietnam \\ ${ }^{1}$ Faculty of Applied Sciences, Ton Duc Thang University, Vietnam \\ ${ }^{2}$ Electronics and Electrical Communications Engineering Department, Faculty of Electronic Engineering, \\ Menoufia University, Egypt
}

\begin{tabular}{lll}
\hline \hline Article Info & ABSTRACT \\
\cline { 1 - 2 } Article history: & $\begin{array}{l}\text { This study has outlined the simulative study of simple ring resonator based } \\
\text { Received Jan 20, } 2019\end{array}$ & $\begin{array}{l}\text { Brewster plate in the air. The obtained results are achieved with the } \\
\text { variations of space length, curvature radius, and phase angle of the spherical } \\
\text { Revised Mar 17, 2019 }\end{array}$ \\
$\begin{array}{l}\text { mirror. Beam radius criterion and stability parameters are measured with the } \\
\text { variations of refractive index and thickness of Brewster plate in the air. } \\
\text { The negative and positive effects of increasing operating parameters are } \\
\text { observed on the performance of ring resonator system efficiency. }\end{array}$
\end{tabular}

Back mirror

Brewster plate

Ring resonator

Spherical mirror

Copyright $@ 2019$ Institute of Advanced Engineering and Science. All rights reserved.

Corresponding Author:

Ahmed Nabih Zaki Rashed,

Electronics and Electrical Communications Engineering Department,

Faculty of Electronic Engineering,

Menouf 32951, Menoufia University, Egypt.

E-mail: ahmed_733@yahoo.com

\section{INTRODUCTION}

The previous studies concentrate on the performance parameter for ring resonators that are namely factor quality, resonance frequency and tunneling frequency [1-5]. The resonance frequency of this circuits resonance is determined by the exacting of two elements such as inductors and capacitors. The gain in the resonance case is high [6-9]. Some resonator circuits composed from resistors, inductors, and capacitors that are different in values. Many types of research are attempted to measure the best candidate values of these components for resonator circuits to have a high gain [10-12].

Another important parameter in the resonator circuit is the quality factor which is in relation to the resonance frequency of the circuit resonance [13-15]. The quality factor is estimated by the multiplication of the resonance frequency with inductance value and divided by resistance value. The larger inductance value the greater quality factor [16, 17]. The lower the resistance value the greater the quality factor [18, 19]. The resonance frequency is determined by the square root of the division of inductance value on the capacitance value. More attempts for increasing the quality factor the ring resonators [20].

\section{RING RESONATOR DESCRIPTION AND RESEARCH METHOD}

Figure 1 has presented the basic schematic view of the simple ring resonator. L1 is the space length which is ranged from $100 \mathrm{~mm}$ to $1200 \mathrm{~mm}$. M1 is the spherical mirror with $\mathrm{R}$ is the curvature radius of the mirror and alpha is the phase angle of the spherical mirror in degree. The curvature radius is positive for 
concave mirror and negative for a convex mirror. The alpha phase angle ranges from 1 degree to 10 degrees. $\mathrm{d} 1$ is the space length between the spherical mirror and Brewster plate in the air whose thickness ranges from $1 \mathrm{~mm}$ to $10 \mathrm{~mm}$ and its refractive index ranges from 1.3 to $1.5 \mathrm{~d} 2$ is the space length between the Brewster plate in the air and spherical mirror M2 whose R parameter is the curvature radius of the mirror and alpha parameter is the phase angle of the spherical mirror in degree.

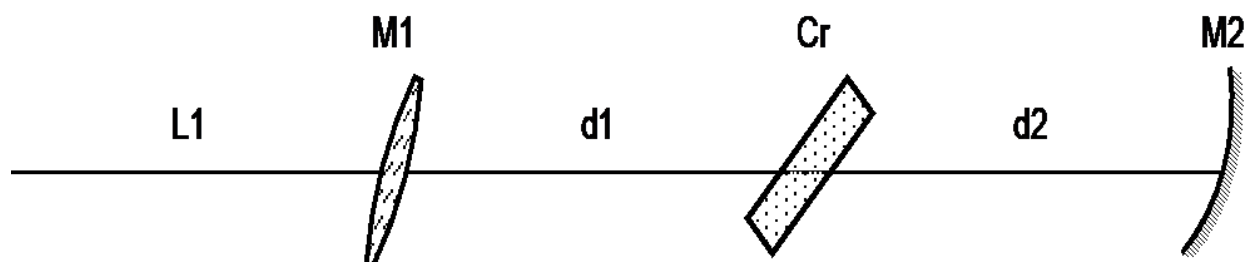

Figure 1. Basic schematic view of the simple ring resonator

So M1, M2 are the spherical mirrors with $\mathrm{R}$ parameter is the curvature radius of the mirror and alpha parameter is the phase angle of the spherical mirror in degree. $\mathrm{L} 1, \mathrm{~d} 1, \mathrm{~d} 2$ represents the space lengths between resonator elements in mm units. Usually, its values range from $100 \mathrm{~mm}$ to $1200 \mathrm{~mm}$ or less than values in other applications. While the different elements in the simple resonator system are the Brewster plate in the air whose its thickness $(\mathrm{t})$ measured in $\mathrm{mm}$ and $\mathrm{n}$ is the refractive index.

\section{RESULTS AND ANALYSIS}

We have presented the simulative study of simple ring resonator based Brewster plate in the air. The variation of space length and empty space are applied in the range of $100 \mathrm{~mm}$ to $50 \mathrm{~mm}$. The variations of curvature radius and phase angle of spherical mirrors are applied to measure the stability criterion and beam radius over the stability region. As shown in Figure 2, the beam radius variations versus empty space variations in $\mathrm{S}$ plane and $\mathrm{T}$ plane. It is clear beam radius radiation increases with increasing empty space in both planes under study. The variations of beam radius against variations of the curvature radius of the spherical mirror are shown in Figure 3. A curvature radius of spherical mirror increases leading to a decrease in beam radius variations in $\mathrm{S}$ plane and $\mathrm{T}$ plane. The beam radius variations in relation to variations of the phase angle of the spherical mirror as shown in Figure 4. It is observed that as the phase angle of the spherical mirror increases leading to an increase of beam radius in the $\mathrm{S}$ plane and slightly decrease and increase in $\mathrm{T}$ plane.

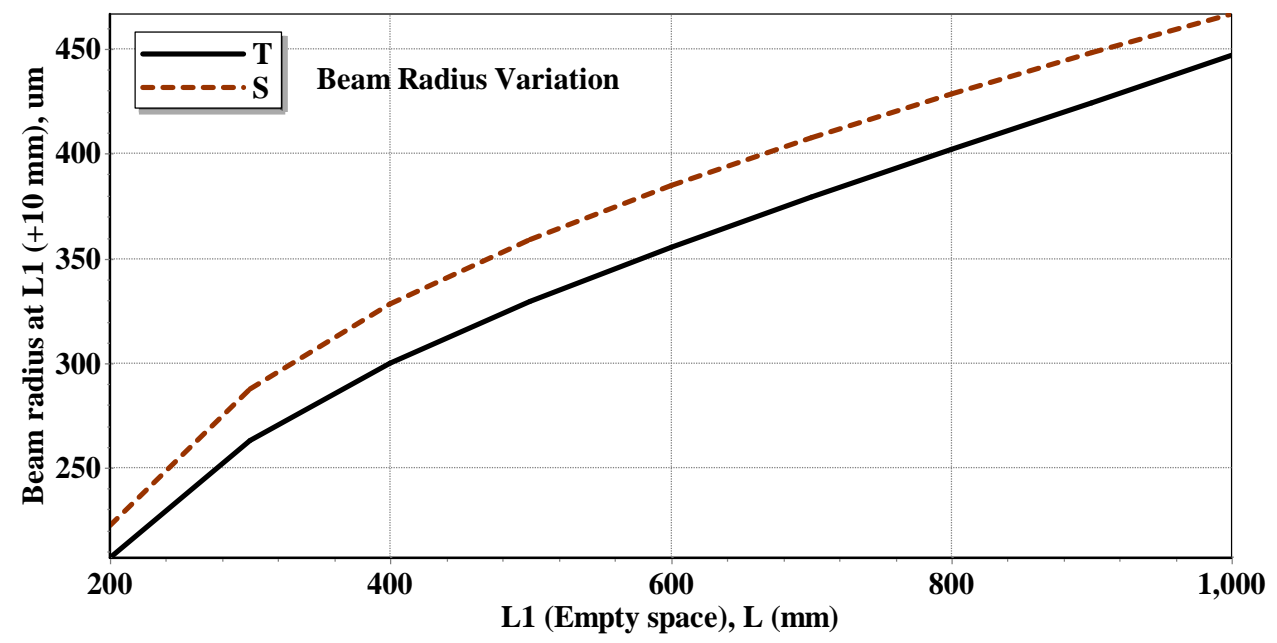

Figure 2. Beam radius variations versus empty space variations in $\mathrm{S}$ plane and $\mathrm{T}$ plane 


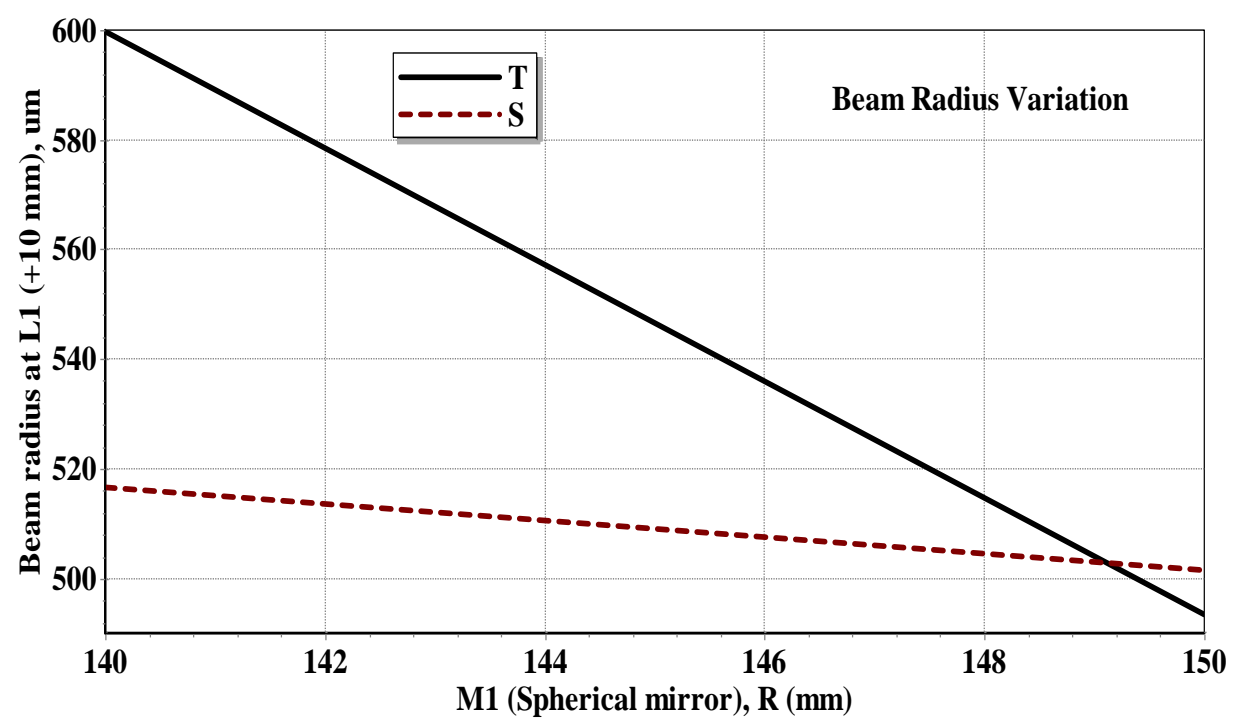

Figure 3. Variations of beam radius against variations of the curvature radius of the spherical mirror

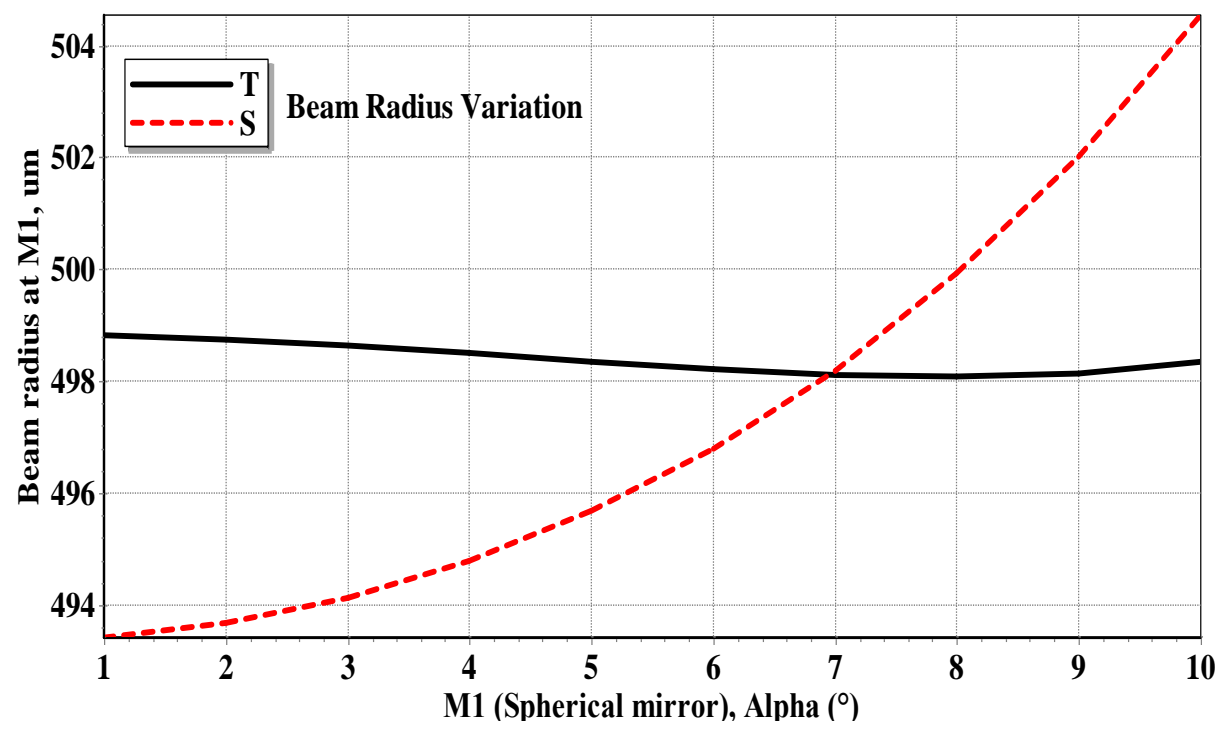

Figure 4. Beam radius in relation to variations of the phase angle of the spherical mirror

Figure 5 shows the variations of beam radius versus variations of empty space. As empty space increases leading to a decrease of beam radius that ranges from $450 \mu \mathrm{m}$ to $630 \mu \mathrm{m}$ in $\mathrm{T}$ plane only. There are no variations of beams radius radiation in $S$ plane. Figure 6 shows the beam radius variations in relation to refractive index variations of Brewster plate in the air. As refractive index variations of Brewster plate in air increases leading to an increase of beam radius in both $\mathrm{S}$ and $\mathrm{T}$ planes. Beam radius has a greater value in $\mathrm{T}$ plane in compared with the $S$ plane. The variations of stability criterion against variations of empty space variations as shown in Figure 7. As empty space increases from $50 \mathrm{~mm}$ to $90 \mathrm{~mm}$ this leading to stability parameter increases in $\mathrm{T}$ plane and $\mathrm{S}$ plane. But from empty space ranges from $90 \mathrm{~mm}$ to $150 \mathrm{~mm}$ this leading to stability parameter decreases in both $\mathrm{S}$ and $\mathrm{T}$ planes. 


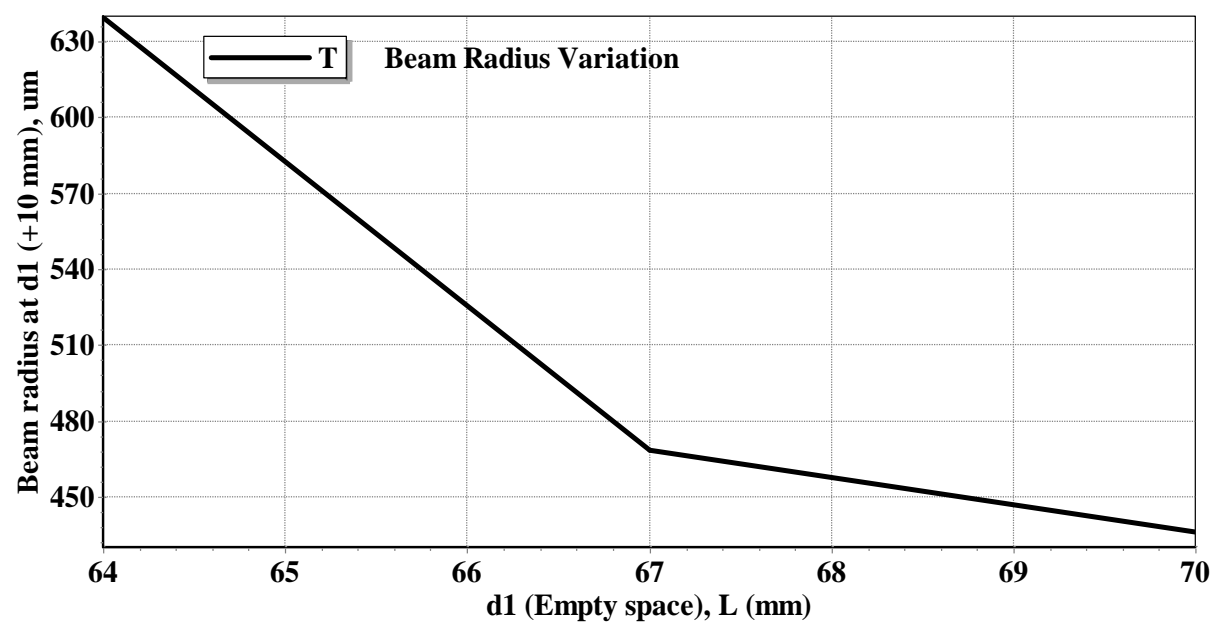

Figure 5. Variations of beam radius versus variations of empty space

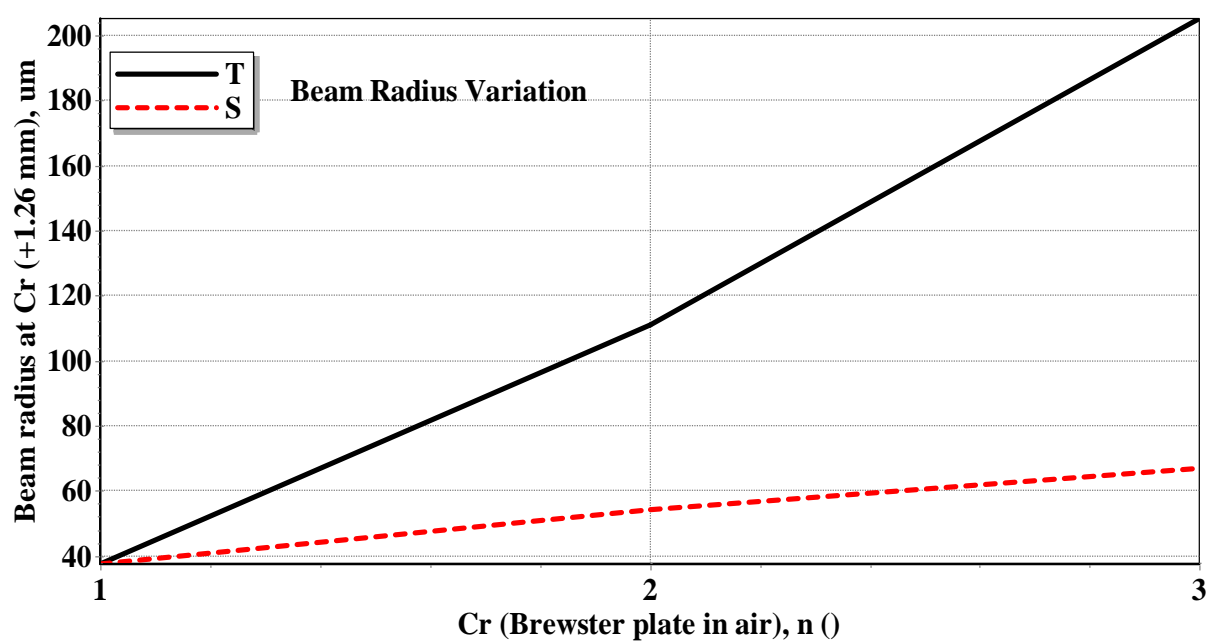

Figure 6. Beam radius variations in relation to refractive index variations of Brewster plate in the air

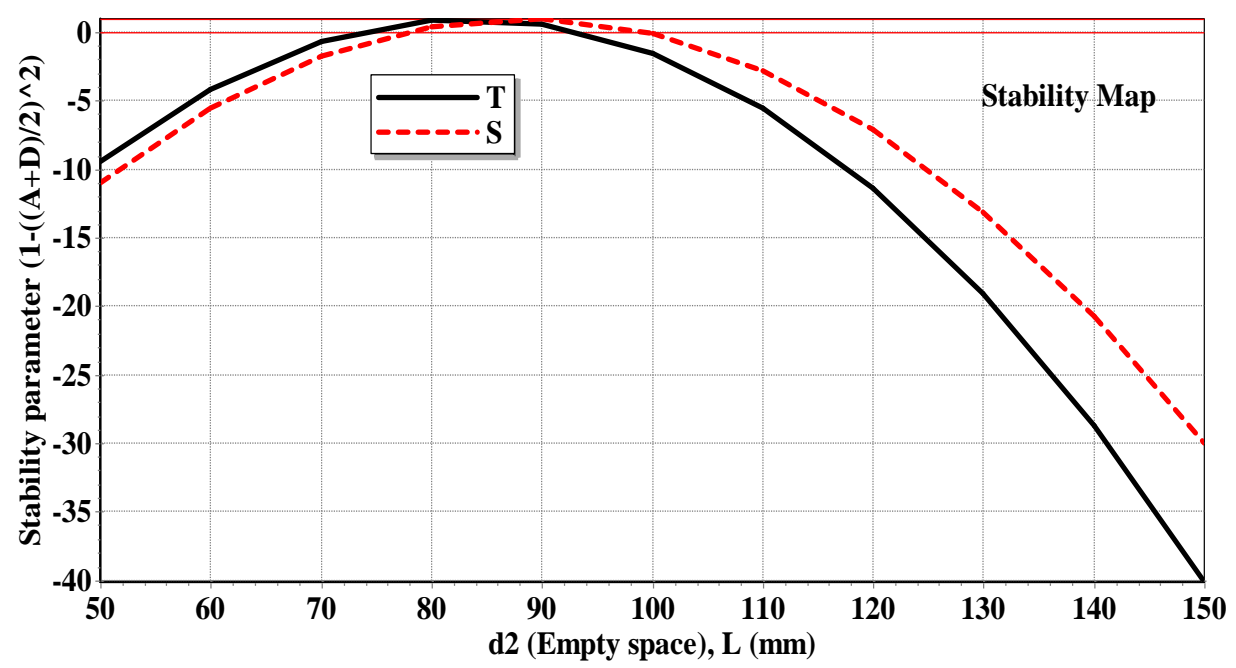

Figure 7. Variations of stability criterion against variations of empty space variations 


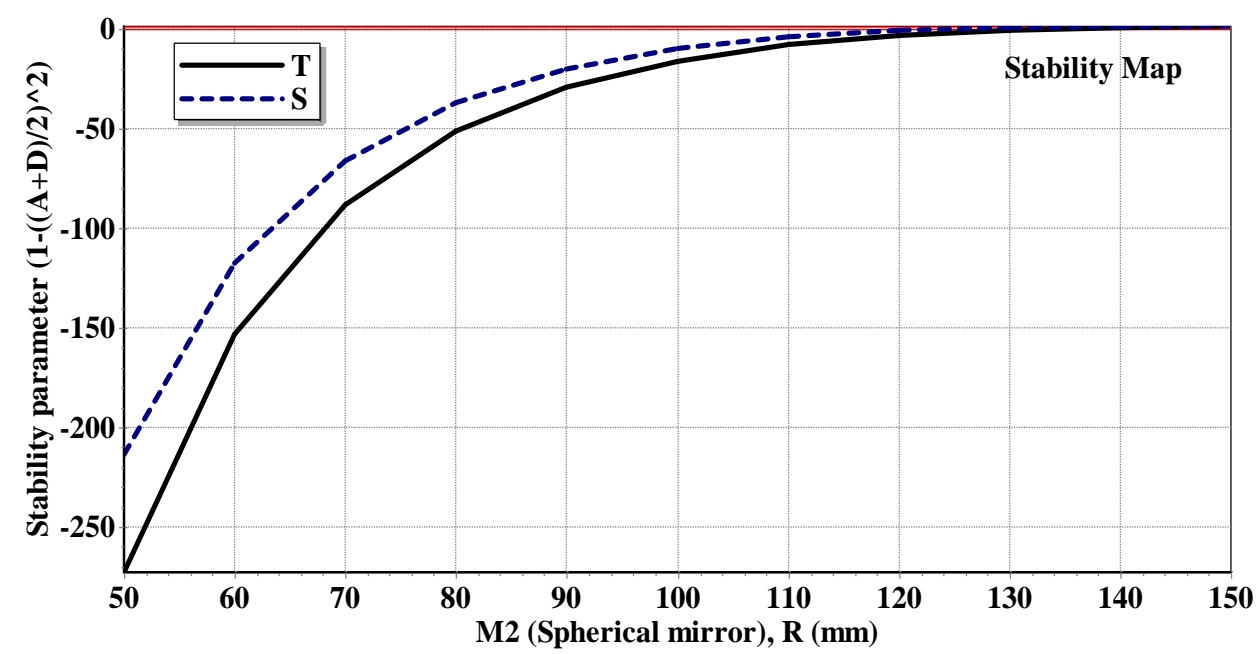

Figure 8 . Stability criterion in relation to the curvature radius of spherical mirror variations

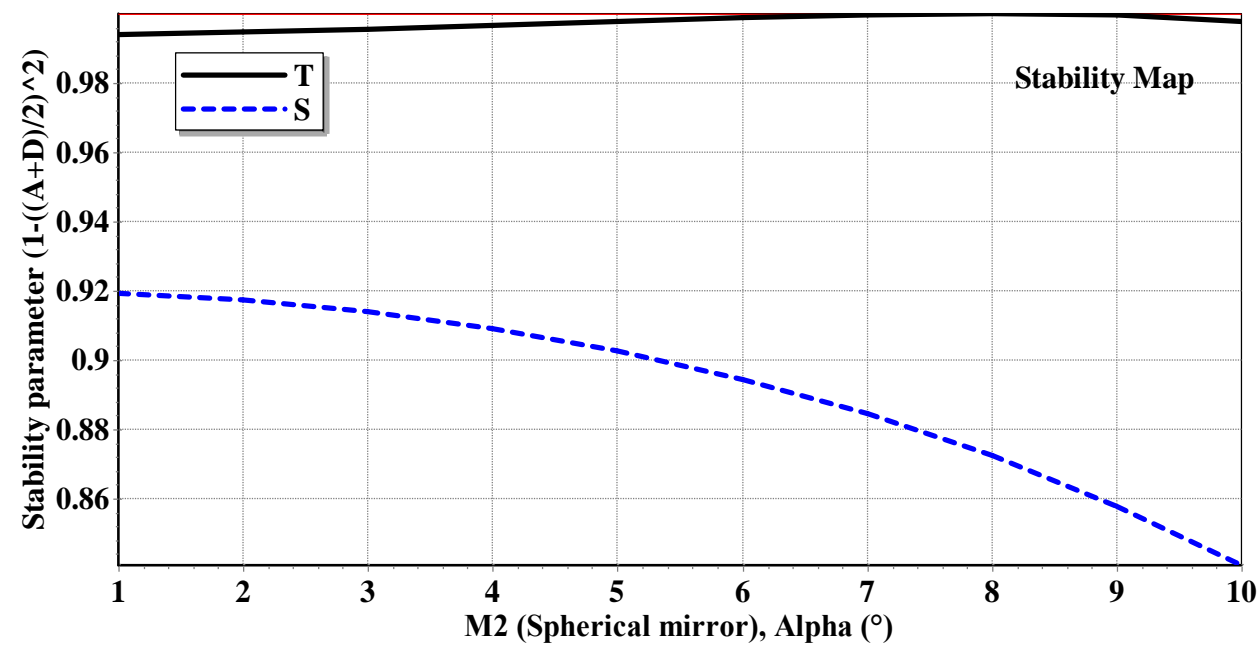

Figure 9. Stability parameter variations versus phase angle variations of the spherical mirror

Figure 8 clarifies the stability criterion in relation to the curvature radius of spherical mirror variations. It is observed that the stability parameter increases in both $\mathrm{S}$ and $\mathrm{T}$ planes from the curvature radius ranges from $50 \mathrm{~mm}$ to $120 \mathrm{~mm}$. But stability parameter is almost constant from the curvature radius ranges from $120 \mathrm{~mm}$ to $150 \mathrm{~mm}$. Stability parameter variations versus phase angle variations of the spherical mirror is shown in Figure 9. As phase angle of spherical mirror increases leading to decreases in stability parameter in $\mathrm{T}$ plane. But stability parameter increases with increasing of the phase angle of the spherical mirror from 1 degree to 7 degrees. While the performance degraded from the phase angle of spherical mirror variations from 8 degrees to 10 degrees.

\section{CONCLUSION}

In summary, the simple ring resonator is simulated based on a Brewster plate. It is clear that the positive or negative effects of the operating performance parameters on the simple ring resonator system performance efficiency. Stability parameter and beam radius variations are measured in both $\mathrm{S}$ and $\mathrm{T}$ planes. The stability parameter increases in both $\mathrm{S}$ and $\mathrm{T}$ planes from the curvature radius ranges from $50 \mathrm{~mm}$ to 120 $\mathrm{mm}$. But stability parameter is almost constant from the curvature radius ranges from $120 \mathrm{~mm}$ to $150 \mathrm{~mm}$. The phase angle of the spherical mirror increases leading to decreases in stability parameter in the $\mathrm{T}$ plane. 
But stability parameter increases with increasing of the phase angle of the spherical mirror from 1 degree to 7 degrees. While the performance degraded from the phase angle of spherical mirror variations from 8 degrees to 10 degrees.

\section{REFERENCES}

[1] I. T. Lima, et al., "A Receiver Model for Optical Fiber Communication Systems With Arbitrarily Polarized Noise," Journal of Lightwave Technology, vol. 23, no. 3, pp. 1478-1490, Mar 2005.

[2] S. Norimatsu and M. Maruoka, "Accurate Q-factor Estimation of Optically Amplified Systems in the Presence of Waveform Distortions," Journal of Lightwave Technology, vol. 20, no. 1, pp. 19-27, Jan 2002.

[3] S. M. Jahangir Alam, et al., "Bit Error Rate Optimization in Fiber Optic Communications," International Journal of Machine Learning and Computing, vol. 1, no. 5, pp. 435-440, Dec 2011.

[4] Z. Kornain, et al., "The Simulation of Indoor Service Range Prediction of Wireless Radio Access Point for Radio over Fiber System," IACSIT International Journal of Engineering and Technology, vol. 5, no. 1, pp. 136-140, Feb 2013.

[5] Ahmed Nabih Zaki Rashed, "High Performance Photonic Devices For Multiplexing/Demultiplexing applications in Multi Band Operating Regions," Journal of Computational and Theoretical Nanoscience, vol. 9, no. 4, pp. 522531, April 2012.

[6] S. M. J. Alam, et al., "Improvement of Bit Error Rate in Fiber Optic Communications," International Journal of Future Computer and Communication, vol. 3, no. 4, pp. 281-286, Aug 2014.

[7] Ahmed Nabih Zaki Rashed, and Mohamed A. Metwae'e, "Optical Filters Dimensions and Thermal Operation Conditions Impact on Its Transmission Considerations in Near Infrared (NIR) Optical Spectrum Transmission Region," Optoelectronics and Advanced Materials Journal-Rapid Communications, vol. 8, no. 3-4, p. 175 - 184, March-April 2014.

[8] A. Taya, et al., "Design and Analysis of Low Power Universal Line Encoder \& Decoder," Microelectronics and Solid State Electronics Journal, vol. 5, no. 1, pp. 7-13, 2016.

[9] C.T. Manimegalai and S. G. Kalimuthu, "Underwater Optical Channel Analysis Using DPIM \& PPM," European Journal of Applied Sciences, vol. 9, no. 3 pp.154-162, 2017.

[10] M. V. Raghavendra, et al., "Estimation of Optical Link Length for Multi Haul Applications," International Journal of Engineering Science and Technology, vol. 2, no. 6, pp. 1485-1491, 2010.

[11] E. Feltin, et al., "Blue Lasing at Room Temperature in an Optically Pumped Lattice Matched AlInN/GaN VCSEL Structure," Electron. Lett., vol. 43, pp. 924-926, 2007.

[12] J.-T. Chu, et al., "Room-Temperature Operation of Optically Pumped Blue Violet GaN Based Vertical Cavity Surface Emitting Lasers Fabricated by Laser Lift Off," Jpn. J. Appl. Phys, vol. 45, pp. 2556-2560, 2006.

[13] J.-T. Chu, et al., "Emission Characteristics of Optically Pumped GaN Based Vertical Cavity Surface- Emitting Lasers," Appl. Phys. Lett., vol. 89, pp. 1-3, 2006.

[14] M. C. Shih and C. S. Chen, "A Semiconductor Soliton Cavity Laser Diode and its Output Characteristics," Japanese Journal of Applied Physics, vol. 50, no. 4, pp. 17-22, 2011.

[15] C.-C. Kao, et al., "The Lasing Characteristics of GaN Based Vertical Cavity Surface Emitting Laser With AlN$\mathrm{GaN}$ and $\mathrm{Ta}_{2} \mathrm{O}_{5}-\mathrm{SiO}_{2}$ Distributed Bragg Reflectors," IEEE Photon. Technol. Lett., vol. 18, no. 7, pp. 877-879, 2006.

[16] S.-C. Wang, et al., "Optically Pumped GaN Based Vertical Cavity Surface Emitting Lasers: Technology and Characteristics," Jpn. J. Appl. Phys., vol. 46, pp. 5397-5407, 2007.

[17] T.-C. Lu, et al., "CW Lasing of Current Injection Blue GaN Based Vertical Cavity Surface Emitting Laser," Appl. Phys. Lett., vol. 92, pp. 1-3, 2008.

[18] Christopher J. Stapels, et al., "CMOS Based Avalanche Photodiodes for Direct Particle Detection," Nuclear Instruments and Methods in Physics Research A, vol. 579, no. 1, pp. 94-98, Aug. 2007.

[19] A. Pulvirenti, et al., "Characterization of Avalanche Photodiodes (APDs) for the Electromagnetic Calorimeter in the ALICE Experiment," Nuclear Instruments and Methods in Physics Research A, vol. 596, no. 1, pp. 122-125, Oct. 2008.

[20] Abd El-Naser A. Mohammed, et al., "Transient behavior and transmission bit rates analysis of optoelectronic integrated devices laser diode (LD) and light emitting diode (LED) under amplification and ionizing irradiation environments," Journal of Electrical and Electronics Engineering Research, vol. 3, no. 7, pp. 121-133, 2011.

\section{BIOGRAPHIES OF AUTHORS}

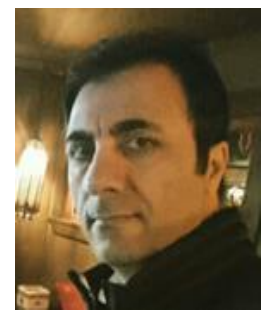

Dr. IS Amiri has been doing research on several topics such as the optical soliton communications, laser physics, fiber lasers, fiber grating, electro-optical modulators, nanofabrications, semiconductor design and modelling, Lumerical modelling, plasmonics photonics devices, nonlinear fiber optics, optoelectronics devices using 2D materials, semiconductor waveguide design and fabrications, photolithography fabrications, E Beam lithography, quantum cryptography and nanotechnology engineering. 


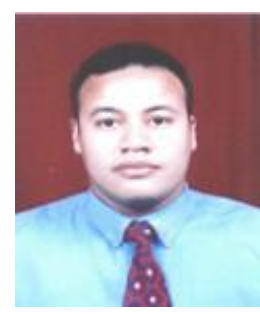

Assoc. Prof. Ahmed Nabih Zaki Rashed was born in Menouf city, Menoufia State, Egypt country in 23 July, 1976. Received the B.Sc., M.Sc., and Ph.D. scientific degrees in the Electronics and Electrical Communications Engineering Department from Faculty of Electronic Engineering, Menoufia University in 1999, 2005, and 2010 respectively. Currently, his job carrier is a scientific lecturer in Electronics and Electrical Communications Engineering Department, Faculty of Electronic Engineering, Menoufia university, Menouf. Postal Menouf city code: 32951, EGYPT. His scientific master science thesis has focused on polymer fibers in optical access communication systems. Moreover his scientific $\mathrm{Ph}$. D. thesis has focused on recent applications in linear or nonlinear passive or active in optical networks. His interesting research mainly focuses on transmission capacity, a data fate product and long transmission distances of passive and active optical communication networks, wireless communication, radio over fiber communication systems, and optical network security and management. He has published many high scientific research papers in high quality and technical international journals in the field of advanced communication systems, optoelectronic devices, and passive optical access communication networks. His areas of interest and experience in optical communication systems, advanced optical communication networks, wireless optical access networks, analog communication systems, optical filters and Sensors. As well as he is editorial board member in high academic scientific International research Journals. Moreover he is a reviewer member in high impact scientific research international journals in the field of electronics, electrical communication systems, optoelectronics, information technology and advanced optical communication systems and networks. His personal electronic mail ID (Email:ahmed_733@yahoo.com). His published paper under the title "High reliability optical interconnections for short range applications in high performance optical communication systems" in Optics and Laser Technology, Elsevier Publisher has achieved most popular download articles in 2013. 